\title{
nome \\ Quality of Work Life and Work Process of Assistance Nurses
}

\author{
Denisse Parra-Giordano ${ }^{1 *}$, Denisse Quijada Sánchez ${ }^{2}$ Patricia Grau Mascayano ${ }^{3}$ and Daniela Pinto-Galleguillos ${ }^{4}$ \\ 1 Departamento de Enfermería. Universidad de Chile. Av. Independencia, Santiago, Chile; drparra@uchile.cl \\ 2 Departamento de Enfermería. Universidad de Chile. Av. Independencia, Santiago, Chile; dquijada@uchile.cl \\ 3 Departamento de Enfermería. Universidad de Chile. Av. Independencia, Santiago, Chile; patri- \\ cia.grau@uchile.cl \\ 4 Programa de Microbiología y Micología, Facultad de Medicina, Universidad de Chile. Av. Independencia, \\ Santiago, Chile; dpintogalleguillos@gmail.com \\ * Correspondence: drparra@uchile.cl
}

\begin{abstract}
Background: The concept of Quality of Work Life (QWL) has been built multidimensionally through social reproduction; it is impacted by the perceptions of each individual and by the relationship between workers and the work environment. Objective: to analyze the Work Process and QWL of assisting nurses in public health. Methods: Research in a critical paradigm, descriptive, exploratory with a qualitative approach. The population corresponds to Nurses who work in care work. Semi-structured guiding questions were applied and were analyzed with content analysis. Results: seven participants declared female; all Chilean; seven are young adults; six singles; only one has children, and one has a person dependent on her care; six are heads of household, and five receive help with housework. All have a nursing degree, five have a diploma, but none have a postgraduate. Work Process has three subcategories: work object, instrument, organization, and work conditions; the QWL category has six subcategories: definition and perception of QWL, QWL potentiating factors, QWL exhausting factors, QWL improvement strategies, the emotional burden associated with QWL, and Health problems. Conclusions: In this way, the lifestyle built by the assistance in the health area has repercussions on the quality of life and health in general.
\end{abstract}

Keywords: Occupational Health; Quality of Life; Nurses; Working Conditions; Work; Primary Health Care.

\section{Introduction}

Work is a central aspect of life, being a means to obtain social and economic benefits and position individuals in society, determining their acquisitive power [1].

The concept of Quality of Work Life (QWL) has been multidimensionally constructed through social reproduction, which determines their social insertion historically, considering the work performed by each person [2]. QWL is promoted by favorable working conditions [3], impacted by the perceptions and feelings of each individual [4], and by the relationship between workers and the work environment [5]. The QWL is also understood as the worker's satisfaction with their personal and work needs in the work process in a given position [6]. Must be valued and respected by the employer [4].

In the health care system, nursing is the largest workforce [5,7]. Therefore, QWL is essential for the Nurse, recognized as the degree to which their personal needs are satisfied through quality care and organizational objectives [7,8]. However, many factors influence it [5]. Likewise, the nursing QWL plays a fundamental role in managing care [9], increases productivity, and reduces turnover and psychosocial impact $[6,8]$.

Although it is thought that nurses, having the necessary knowledge and means, should provide an optimal QWL, different problems arise in their work development [10]. Likewise, globalization has brought changes in employment conditions and nursing work processes under the axis of capitalism, which has implied transformations in the work profile, and workers to adapt to the current economic model [11]. 
Nursing evolved from a trade to a professional career, the work of Florence Nightingale being decisive in the formation of Modern Nursing. Under this model, nursing develops in five work processes: care, management, teaching, research, and political participation [11]. The Work Process has three elements: the work object where the activity is carried out; the instruments that are a set of tools between the worker and the object; the action that refers to work, its specific organization for a particular purpose and the conditions in which it is carried out [1]. Thus, for example, the healthcare nurse transforms the object (subject) using specific knowledge and own instruments.

The QWL of people is a historical and social result. On the other hand, the QWL of a group is determined by the time of life and work of everyone in society. Therefore, in terms of her work, each person develops a contradictory system of opposing forces of favorable and destructive processes that impact their Quality of Life (QoL) [11].

In this context, nurses' work situation is impacted by how health institutions are inserted into the labor market, influencing working conditions, explicitly nursing as a social practice. Regarding the working conditions of nurses, the Labor Code regulates the legal processes [12], and the Health Code [13] establishes the areas covered by article 113 "includes the management of care concerning promotion, maintenance, and restoration of health, prevention of diseases and injuries."

Professional burnout is a syndrome that has been the subject of many investigations which was various impacts on their work and professional lives [14,15]. For example, direct care work is recognized as a source of occupational risk [14], even more so as nursing closest to the sick person [15]. Describing dissatisfaction with work, physical and emotional exhaustion [15], likewise, interference in family life.

The neoliberal economic model impacts the work of nursing; the consumer society encourages workers to have new houses, cars, and others. The National Research on Employment, Labor, Health, and Quality of Life of workers in Chile (2009-2010), refers that the worst evaluated aspects are the amount of money that enters the home and the level of debt [16]. In this way, healthcare nurses look for work sources outside the working day and in other institutions, taking time for family dedication and rest that impacts QWL.

Like any work process, care nursing is a generator of favorable and destructive factors $[14,15]$. Therefore, the care nurse must know how working conditions affect the QoL and improve the quality of care delivered to the beneficiary population in the health network. Likewise, this knowledge will also promote health at work; these are direct contributions to the development of nursing in its practical and social context.

Regarding the development of care, in Chile, a professional can develop in the three maintenance levels of the health network [17]. Furthermore, most studies are produced at the tertiary level, making it essential to carry out an approximation at the primary level.

In this way, the change in the labor market, the increase in nursing professionals working in care in Chile, which has implied growth in the role of nursing in the care and other areas of competence, raises the need to analyze the Work Process and Quality of Work Life of care nurses. Therefore, this work aims to analyze the work process and QWL referred by care nurses in public health.

\section{Materials and Methods}

Research in a critical paradigm, descriptive, exploratory with a qualitative approach.

Carried out in two Family Health Centers Primary level of care and a Type four Hospital of Santiago de Chile's Western Metropolitan Health Service. The population corresponds to Nurses and Nurses who work in care work. Inclusion criteria: workday 2233-44 hrs, care exercise for at least six months in the workplace. Exclusion criteria: Professionals on vacation or medical leave.

Instrument: the researchers, according to the literature review, established two previous study categories, work process and quality of work life. Then, they applied the guiding questions to nurses with the same characteristics to adjust their relevance to the object 
of study. Thus, the researchers asked sociodemographic characterization questions and two semi-structured guiding questions: What is your work process at the primary level in public health services? And, What is your perception of the quality of working life at the primary level in public health services?

Data collection: The researchers contacted the head nurse of each institution to coordinate the interviews, inviting all nurses in each workplace to participate. According to time availability, individual interviews were agreed upon, developed by the researcher without a prior relationship with participants. After explaining and signing the informed consent, five interviews were conducted at the Primary Health Care (PHC) of care and three at the tertiary level until the object of study was saturated. The participants agreed to participate in the investigation (there were no refusals or desist from the interviews) in a room of each institution with total privacy. With a duration of 17 to 37 minutes, from April 2019 to December 2020. They were recorded and transcribed to guide the analysis.

Data analysis: The researchers analyzed the sociodemographic data with descriptive statistics and the interviews with content analysis methodology according to Bardin [18], considering the predefined and emerging categories. According to the analysis developed from the interviews, they obtained three subcategories from the previous Work Process categories: work object, instrument, organization, and work conditions; The Quality of Work Life category is made up of five subcategories: definition and perception of QWL, QWL potentiating factors, exhausting factors of QWL, QWL improvement strategies and emotional burden associated with QWL. Likewise, the emerging category of Health problems emerges. The investigators identified each interview with the letter E, according to the consecutive number.

Aspects of rigor and ethics: the rigor criteria of the study according to Guba [19] were applied.

\section{Results}

This research had eight participants (eight interviews). Concerning the sociodemographic characterization, seven of the eight participants are female, and all are Chilean; seven are young adults ( 30 years old), and one average adult (54 years old). In addition, six are single, one married and one separated, six as a couple; only one has children and one person dependent on her care; six are heads of household, and only five receive help with housework. Regarding professional training, all have a nursing degree from different universities, five have a diploma, but none have a postgraduate degree.

\subsection{Category 1. Work Process}

The work process is built by the object, instruments, organization, and working conditions. The first is defined as gratification and pride for work, commitment, and vocation with the care of people. The instruments can come from the institution or be personal. And in terms of organization and working conditions, it is identified: working hours, distribution of Tasks, salary, environment, request for permits and perception of medical licenses, support for training and well-being, Labor relations.

\subsubsection{Subcategory 1.1 - Work object}

"For me, my goal is to give a good quality of care to the person." E7

\subsubsection{Subcategory 1.2 - Work Instruments}

"What I need is a box first of all, because if not, I can't. Computer, I use my cell phone a lot; it's a great tool that helps me a lot because I'm connected to the mail all the time, which drives me. And schedules, notebook". E3

\subsubsection{Subcategory 1.3 - Organization and division of work}

Six have a day shift, and two have a shift system; Work seniority ranges from 23 to 1 year, with 12 to 1 year at the institution. Regarding the development of their work, three are sector nurses; two are in charge of the transversal program, one is in order of the shift, and two are clinical floor nurses. According to the commute to work, the minimum time 
is 15 minutes, and the maximum is 90 minutes, four use public transport, three own cars, and a bicycle. Salaries also present a variability from $\$ 950$ and $\$ 1,650$.

"The director chooses the positions. The director is the one who appoints you, and you are in charge of several tasks. Mostly, the unit boss manages the plan and my schedule. He is the one who sees your plans, blockades, your administrative hours, the hours that you see patients, etc. ". E3

"I find work-relations good in general and, like in most places, there are always frictions within some people due to their personalities, I think, but in general, it is good. I don't know, but if I start to compare other places' stories, I find that the atmosphere here is good. " E5

3.2. Category 2: Quality of Work Life - QWL

The QWL is formed based on the definition and perception, potentiating factors, exhausting factors, and emotional charge.

3.2.1. Subcategory 2. 1 - Definition and perception of QWL

"Quality of life I believe that when one feels as good, as full in what one does, what he is doing. If he is with the individual part well, I think that is what it is, quality of life. I believe that it is not pure to work, but to have a little of everything, that is, to have time with the family, go out, have fun, for everything, and work too. " $\mathrm{E} 4$

3.2.2. Subcategory 2.2 - Potentiating factors QWL

"Yes, first of all, the work environment is favorable, I find it to be good, the conditions. I feel that this building is wonderful, everything is very clean. I have all the necessary resources to work well; I have nothing to complain about." E5

3.2.3. Subcategory 2.3 - Exhausting factors (negatively affect) the QWL

"I think personal relationships have a lot of weight, that is, relationships with your peers, with the heads, especially with the heads." E3

"I consider that my work is exhausting because it is twelve long hours of work." E8

3.2.4. Subcategory 2.4 - QWL improvement strategies

These can be from the company or personal.

"Do a workshop, go to an activity that helps us to channel our emotions a little." E1

3.2.5. Subcategory 2.5 - The emotional burden associated with QWL

"Or sometimes you can't cope with seeing all of them. Then you have to do a TRIAGE on who is worse, who comes later then maybe that is a burden as well as vital because it depends on you that the doctor sees that patient on the day Today, or why don't you see him first and not this one, then there are times when the patients are both super serious. You don't know who to prioritize. That is sometimes a bit harder. " E1

3.3. Category 3 - Health problems associated with work

It refers to health problems identified with an occupational cause by the interviewees.

"I was with a depression, a depression together with an anxiety disorder that was produced by an occupational disease, by a workplace harassment, I was 3 to 4 months on leave, with psychiatric treatment." E3

\section{Discussion}

Sociodemographic and labor characteristics

In various studies on nursing care work, the majority were women, Mexico 95,7\% [20], Saudi Arabia 95\% [21], China 94\% [9], Malaysia 93\% [22], Tehran Iran 90\% [23], Kashan Iran 83\% [24], Brasil 83\% females [25], Chile 83\% [26], Irak 73\% [4], Libano 60\% [27]. In contrast, in Ethiopia, 51\% were men [8].

Regarding the average age of 30 years [8], 31 years [4,22], were 35 years old or younger [21], Copiapó Chile between 20 and 30 years [28], age between 20 and 55 years [9], mean age 39 years [5,20], mean age 33 years [24], mean age 41 years (22-64 mean age was 33 years [26]. 
Concerning marital status, 58\% were single [8], 47\% single [28], 53\% were married [22], 57\% married [4], 73\% married [27], 71\% were married [9], were married, and only $23 \%$ were single [21], $66 \%$ were married or in a relationship and $68 \%$ had children[25], $57,1 \%$ reported living with a partner [20]. Regarding children, $62 \%$ had no children [22], $6 \%$ were pregnant, $13 \%$ were breastfeeding, and $8 \%$ had children under two years of age, while approximately half of $51.83 \%$ had responsibilities for the care of the elderly[9].

Regarding work experience, $85 \%$ with less than six years of experience [22], $41 \%$ with less than five years of work experience [23], seven years within the institution [4], and $85 \%$ had three or more years of work experience [9], average seniority of 5 years in the position [26], 36\% presented from 1 to 4 years in the place [25]. In addition, $96 \%$ had a diploma degree [22], graduates [23], 88\% graduates [4], 87\% had a bachelor's degree or higher [9], 71\% had a Baccalaureate degree [27], 40\% had a degree [28], 73\% were graduates, and $27 \%$ graduated [21].

Work Process

Regarding working conditions, $42 \%$ have a renewable fixed-term contract [26], 35\% have a permanent job (social security, labor benefits and are accumulating years of retirement) [20], 32\% had a contract [4], 27\% permanent contract [26]. On the contrary, $65 \%$ have a temporary work contract renewed every six months [20], 20\% fees, and 12\% replacement [26]. Furthermore, 65\% were first degree holders [8], 54\% had a full-time job, $79 \%$ had only one job[20], 72\% had no other employment relationship [25], 80\% worked with a shift system [26], 76\% work hourly shifts [25], 60\% worked rotating shifts [27]. worked more than 40 hours per week [8], although the working day is 30 hours a week, it can reach 50 [25] with the hour shift.

About the average monthly income of \$ 500 [4], 78\% earn between \$1500 to \$ 3000 for full time [26], more than $\$ 1000$ for full time[28]. Complementing $78 \%$ did not receive a risk allowance, $76 \%$ did not receive additional certification compensation, $48 \%$ intended to change the nursing profession, and 19\% did not perceive their profession satisfactorily [8]. Family income level 251,000 and 500,000 35\%, 501,000 and one million 34\%, more than one million $30 \%$ [8].

Definition and perception of $Q W L$

QoL presents a high level, and the highest values are in managerial support and workload (exceeds the theoretical mean) [28]. Nursing QWL is mainly at a moderate level and needs improvement interventions [7,29]. QWL is in the middle range with room for improvement [9]; 70\% of nurses report being satisfied with the dimension environment, QWL, in terms of the organizational culture [5]; well-being is higher in women [9].

On the contrary, more than half of the nurses reported a poor QWL [4,8]. This background implies a greater probability of leaving their job due to dissatisfaction with most of the components of the QWL (adequate and fair pay, safe and hygienic work environment, general atmosphere of work-life and social dependency of work-life) [4].

One of the factors that influence QWL in the Nurse is stress [30]. Contact with death, patients and their families, conflicts with supervisors, and uncertainty about the therapeutic effect significantly increased pressure among participants [31]. Physical health has the best QoL and the lowest environmental field, mainly due to occupational stress [27].

Most PHC nurses are dissatisfied with work and family life factors, spend long hours and are often exhausted after work [6]. In this way, nursing is perceived as strenuous work [31]. In Mexico, a study showed that dissatisfaction could be found in the QoL of the nursing professional in public health clinics in all dimensions. The dimensions with the most significant blow were inclusion in the workplace, personal development, and well-being achieved through work. The dimensions with the minor dissatisfaction were institutional support, free time management, job satisfaction, and job security [20]. In Chile, the perception of Quality of Care is acceptable, and the working environment conditions evaluate as good except for the temperature [26].

QWL potentiating factors 
Organizational commitment has a partial negative mediator between nurses' QWL and intention to change [22]. Managers can improve the QWL by providing opportunities for growth and development of staff skills, providing conditions for greater employee engagement, promoting teamwork, planning fair and equitable pay [23]. The nurses acknowledge that $78 \%$ have received cooperation from their respective departments supporting their QWL [5]. The higher quality of professional life, the greater job satisfaction, presenting a mutual and strengthening relationship between the two [28]. QWL the highest scores were for job and professional satisfaction [9].

QWL of nurses has significant positive associations with: education, marital status, work experience, night shifts, monthly per capita income, support from family members [5]; years of experience (1-3), number of night tasks (5-7 days), number of extraordinary tasks (3-4 days), work on days off, rest at the right time [7]; organizational commitment, positive work environment, and satisfaction of staff [23]. Likewise, the public image of a society, the nursing position, the department of work, educational level, availability of a safe place to rest, availability of drinking water, the factors of age, title, education, employment contract, sleep disorder, and nursing adverse events were associated with a good nursing QWL [8,9].

The QWL of the head nurse is three times better than that of the rest. Furthermore, the QWL of the nurses undergraduate level is 2.3 times more than those who only have a diploma. In addition, the public image of a society, labor department, availability of a safe place to rest, and the availability of drinking water are associated with good QWL [4]; and the socio-professional relationships [25].

Exhausting factors of the QWL

Nursing performance conditions are adverse, which may negatively impact their QWL and staff and the care they provide. They felt helpless knowing the poorly performing care, expressing frustration and intention to change jobs and professions. In this form, it finally ends up having an impact on your QWL and staff [32]. In decreasing order, they are work overload, lack of supplies or poor quality of these, unsatisfactory salaries, number of nursing professionals inadequate to the demand, little clarity in functions, also mentioned as role ambiguity or multitasking, lack of security, lack of recognition, lack of opportunity for promotion, training and/or updating, lack of benefits and rewards, lack of autonomy and participation, and poor organization [32]. Likewise, education, job title, workplace, a second nursing job, and age [27,28] are predictors of low QWL [24].

Time demand, frustration, effort levels, working rotating are significantly correlated with low QWL levels $(24,27)$. The factors that cause dissatisfaction in nurses are inclusion in the workplace, personal development, and well-being achieved through work [20], communication difficulties, access to information to perform tasks, lack of support for professional development, lack of recognition, lousy work environment, and overload; besides, the last three were associated with low back pain [25].

Occupational stress is a significant predictor of low QWL for nurses [9,27,31], while it can also influence patient outcomes [31]. In addition, most studies affirm that the relationship between adverse working conditions and nursing health generates stress and job dissatisfaction. Body pain in the back, lower extremities, migraines, poor performance, discouragement, irritability, and depression [32].

A studying in Bangladesh emerged seven barriers to his working life: heavy workloads; lack of government accommodation and transportation; poor health; lack of support from nursing supervisors; lack of promotional opportunities; incomplete hospital policies and procedures; and lack of night shift and risk allowances [33]. For example, 40\% of nurses wanted to quit their job in Iraq due to these conditions [4]. Therefore, improving QWL is essential to attracting and retaining employees, especially in healthcare [24\}.

QWL improvement strategies

In the first place, administrators must adopt effective strategies to propose favorable working conditions, consider work stressors, promote a better QWL in nursing workers, and optimize their work environments $[4,8,27,33]$. In addition, the use of preventive and 
efficient practices to manage stress seems essential [30], incorporating the levels of commitment to your organization [22], because the organization plays a critical role in determining the health risks associated with burnout syndrome [28].

Maintaining a healthy work-life is crucial for nurses to improve their QWL, increase retention, improve performance and productivity, promote safe nursing care [6], strengthen the educational level, and their awareness of community perceptions of nursing [8]. QWL improvement interventions include: long-term care team talks, empowerment models, integration of focus groups and brainstorming roundtables, positive thinking training, stress inoculation programs, and participatory teamwork [29]; a Stress Inoculation Program proved to be a cheap, safe, and effective way to improve the QWL of nurses [30].

PHC presents important pressure factors for nursing; besides rotation, they must consider developing improvement strategies in the QWL [6]. Interventions to improve the organizational climate will prevent job desertion by directly affecting the QWL; that is, a high QWL will retain the organization's employees [4]. Hospital managers can reform the environment, the programming, and the system according to the different factors that affect the QWL of the nurses, carry out the psychological evaluation, and the appropriate behavioral, psychological intervention for the nurses to improve the QoL [9].

A greater understanding of the nursing work process and its relationship with nonspecific low back pain pointed out that changes must occur in the organization and working conditions to reduce the risks of nursing workers becoming ill [25]. In addition, it is necessary to pay more attention to the low QWL and its related factors, significantly the workload, to understand that a high QWL positively influences the quality of care $[7,20,24,33]$.

The emotional burden associated with QWL

Nurses report the highest frequency of stressful events related to their healthcare team workload [27]. Specific variables can significantly influence QWL, age, marital status, and education, critical in developing programs to improve the quality of work-life of nursing [21]. Thus, ages 41-50 perceive a more significant workload, and those between 20 and 30 have more chronic stress [28].

Regarding psychosocial working conditions, the dimensions with the lowest scores are the regulation and development method, which refer to the workload and the quality of the contract, mainly due to having a fixed-term contract or fees. Being one of the main concerns precisely the contractual one to guarantee job stability and continuity of labor rights [26]. Also, workload and dealing with death are the most common work sources for nurses, resulting in the highest frequency of occupational stressors $[27,28]$. Health problems

While in Chile, $46 \%$ of nursing professionals perceive their health condition as very good and 51\% as good [26]. Nurses describe many problems and barriers that affect their working life, feel the little reward for their hard work, and that their health suffers from their working conditions leading to a low QWL [33].

There is a positive association between work organization and working conditions with low back pain, meaning moderate risks to occupational disease. Likewise, factors that cause job dissatisfaction, such as lack of recognition, lousy work environment, and overload, are associated with low back pain. In addition, those who say they are moody $(83 \%)$, are fatigued $(70 \%)$, and overloaded $(68 \%)$ have low back pain, and this condition increases their low back pain by 6-4-3, respectively. Regarding nutritional status, just over half (52.5\%) are above the BMI considered normal, and only $42 \%$ are normal weight [25].

The main limitation is its realization only from the public perspective, considering integrating private institutions for subsequent investigations, complementing the current one.

\section{Conclusions}


The development of this study allowed us to analyze the Work Process and Quality of Work Life of nursing care in Chilean public health through qualitative design.

Of the participants, all Chilean, the majority declares female gender. They are single young adults, heads of household and receive help in housework, they have a diploma, but none have a postgraduate degree. The Work Process (object, instrument, organization, and working conditions) and QWL describe in six subcategories: definition and perception of QWL, QWL potentiating factors, QWL exhausting factors, QWL improvement strategies, the emotional burden associated with QWL (previous categories), and Health problems (emergent category).

In this way, the lifestyle built by assistance in the health area affects the quality of work-life and health in general. Thus, the present study is an innovative contribution to the development of nursing by making visible how working conditions affect the QWL of healthcare nurses and unveiling the healthcare network's healthcare work process. Considering that nursing care work compromises the QoL of these professionals, the scarcity of studies on QWL in the nursing care network in Chile, it is expected that this study's contributions will be taken as input to deepen the subject.

\section{Patents}

Author Contributions: The four authors of this article participated in the process "Conceptualization; methodology; formal analysis; investigation; resources; data curation; writing-original draft preparation; writing - review and editing; funding acquisition. All authors have read and agreed to the published version of the manuscript."

Funding: "This research was funded by Research Contest of the Nursing Department Universidad de Chile, grant number 2017-1".

Institutional Review Board Statement: "The study was conducted ac-cording to the guidelines of the Declaration of Helsinki, and approved by the Comité de Ética de Investigación en Seres Humanos de la Facultad de Medicina de la Universidad de Chile No. 148-2017 and by the Comité de Ética del SSMO."

Informed Consent Statement: "Informed consent was obtained from all subjects involved in the study."

Data Availability Statement: "Authors have available the recordings of the interviews and all the transcripts of each one of them just as they have the analysis in its entirety."

Acknowledgments: We thank each of the nurses participating in this research for opening their world of work, and those who wished to do so could not participate. In addition, to the respective headquarters that allowed the development of this.

Conflicts of Interest: "The authors declare no conflict of interest."

\section{References}

1. Marx K. El Capital. Crítica de la economía política. Libro tercero: El proceso global de la producción capitalista. Siglo XXI de España Editores; 2017. $1117 \mathrm{p}$.

2. Breilh J. El Debate Determinantes-Determinación: Aportes Del Análisis Teórico, Epistemológico y Político. Rev Fac Nac Salud Pública. 2013;31(1):13-27.

3. Hipólito MCV, Masson VA, Monteiro MI, Gutierrez GL. Qualidade de vida no trabalho: avaliação de estudos de intervenção. Rev Bras Enferm. 2017;70(1):189-97. Doi: 10.1590/0034-7167-2015-0069

4. Faraji O, Salehnejad G, Gahramani S, Valiee S. The relation between nurses' quality of work life with intention to leave their job. Nurs Pract Today. 2017;4(2):103-11.

5. Thakre SB, Thakre SS, Thakre SN. Quality of work life of nurses working at tertiary health care institution: a cross sectional study. Int J Community Med Public Health. 2017;4(5):1627-36. Doi: 10.18203/2394-6040.ijcmph20171775

6. Yunus YM, Idris K, Rahman AA, Lai HI. The role of quality of nursing work life and turnover intention in primary healthcare services among registered nurses in Selangor. Int J Acad Res Bus Soc Sci. 2017;7(6):1201-13. Doi: 10.6007/IJARBSS/v7-i6/3353

7. Hemanathan R, Sreelekha PP, Golda M. Quality of work life among nurses in a tertiary care hospital. Health Car. 2017;5:1-8. Doi: 10.19080/JOJNHC.2017.05.555667

8. Biresaw H, Boru B, Yimer B. Quality of nursing work life and associated factors in Amhara Region Referral Hospitals, Northwest Ethiopia: A cross sectional study. Int J Afr Nurs Sci. 2020;13:100214. Doi: 10.1016/j.ijans.2020.100214 
9. Wang L, Wang X, Liu S, Wang B. Analysis and strategy research on quality of nursing work life. Medicine (Baltimore). 2020;99(6). Doi: 10.1097/MD.0000000000019172

10. Zavala MOQ, Klinj TP, Carrillo KLS. Calidad de vida en el trabajo del personal de enfermería de instituciones públicas de salud. Rev Lat Am Enfermagem. 2016;24. Doi: 10.1590/1518-8345.1149.2713

11. Parra Giordano D, Felli VEA. Work process of nursing professors. Rev Lat Am Enfermagem. 2017;25. Doi: 10.1590/15188345.1941.2946

12. Ministerio de Salud Chile. Código del Trabajo de la República de Chile: Artículo 211, Del seguro social contra riesgos de accidentes del trabajo y enfermedades profesionales. Santiago (CL): Dirección del Trabajo, junio 2013.

13. Ministerio de Salud Chile. Código Sanitario de la República de Chile de 16 de diciembre de 1997: Artículo 113, reglamenta el ejercicio profesional de la Enfermera. Santiago (CL): MINSAL; 1997.

14. Ribeiro RP, Martins JT, Marziale MHP, Robazzi ML do CC. O adoecer pelo trabalho na enfermagem: uma revisão integrativa. Rev Esc Enferm USP. 2012;46(2):495-504. Doi: 10.1590/S0080-62342012000200031

15. da Silva Hanzelmann R, Passos JP. Imagens e representações da enfermagem acerca do stress e sua influência na atividade laboral. Rev Esc Enferm USP. 2010;44(3):694-701. Doi: 10.1590/S0080-62342010000300020

16. Gobierno de Chile MINSAL. Primera Encuesta Nacional de Empleo, Trabajo, Salud y Calidad de Vida de los Trabajadores y Trabajadoras en Chile (ENETS 2009-2010).

17. República de Chile, Ministerio de Salud. Subsecretaría de Redes Asistenciales. División de Gestión de la Red Asistencial. Modelo de Atención Integral de Salud. Serie Cuadernos Modelo de Atención №1. Santiago, Chile; 2005.

18. Bardin L. Análise de Conteúdo. São Paulo: Edições 70; 2011. 280 p.

19. Guba E. Criterios de credibilidad en la investigación naturalista. En: Sacristán JG, Gómez AP. La enseñanza: su teoría y su práctica. 6․ Madrid, España: Ediciones AKAL; 2008. p. 148-65.

20. González-Cruz NL, Peñarrieta-de Córdova MI, Castañeda-Hidalgo H, Flores-Barrios F, Gutierrez-Gomez T, Caballero-Rico F. Quality of work life in primary care of nursing professionals in public health clinics in Tampico, Mexico. J Hosp Adm. 2016;5(3):90. Doi: 10.5430/jha.v5n3p90

21. Albaqawi HM. Quality nursing work life among nurses in Hail Region, Kingdom of Saudi Arabia: Redefining the boundaries of work and life. Adv Soc Sci Res J. 2018;5(3). Doi: 10.14738/assrj.53.4341

22. Alzamel LGI, Abdullah KL, Chong MC, Chua YP. The quality of work life and turnover intentions among Malaysian nurses: the mediating role of organizational commitment. J Egypt Public Health Assoc. 2020;95(1):1-8. Doi: 10.1186/s42506-020-00048-9

23. Hashempour R, Hosseinpour Ghahremanlou H, Etemadi S, Poursadeghiyan M. The relationship between quality of work life and organizational commitment of Iranian emergency nurses. Health Emergencies Disasters. 2018;4(1):49-54. Doi: 10.32598/hdq.4.1.49

24. Sadat Z, Aboutalebi MS, Alavi NM. Quality of work life and its related factors: A survey of nurses. Trauma Mon. 2017;22(3).

25. Cargnin ZA, Schneider DG, Vargas MA de O, Machado RR. Nonspecific low back pain and its relation to the nursing work process. Rev Lat Am Enfermagem. 2019;27. Doi: 10.1590/1518-8345.2915.3172

26. Luengo C, Klijn TP, Burgos M. Calidad del cuidado del profesional de Enfermería y condiciones ambientales y psicosociales de trabajo. Rev Enferm Trab. 2016;6(4):117-25.

27. Anshasi HA, Fawaz M, Alhalalmeh S, Ahmad WQ, Tassi A. Nurses' stressors and their quality of life: A study on nurses caring for older patients. Nurs Open. 2020;7(6):1698-706. Doi: 10.1002/nop2.553

28. Salgado-Roa JA, Lería-Dulčić FJ. Burnout, satisfacción y calidad de vida laboral en funcionarios de la salud pública chilenos. Univ Salud. 2020;22(1):06-16. Doi: 0.22267/rus.202201.169

29. Viselita F, Handiyani H, Pujasari H. Quality level of nursing work life and improvement interventions: systematic review. Enfermeria Clin. 2019;29:223-8. Doi: 10.1016/j.enfcli.2019.06.001

30. Safarzei E, Darban F, Mazloum S. Effect of stress on the nurses' work life quality in psychiatric ward. Iioab J. 2016;7(10):16-21.

31. Sarafis P, Rousaki E, Tsounis A, Malliarou M, Lahana L, Bamidis P, et al. The impact of occupational stress on nurses' caring behaviors and their health related quality of life. BMC Nurs. 2016;15(1):1-9. Doi: 10.1186/s12912-016-0178-y

32. Luengo-Martínez C, Sanhueza O. Condiciones de trabajo y su relación con la calidad del cuidado y salud del profesional de enfermería. Med Segur Trab. 2016;62(245):368-80.

33. Akter N, Akter MK, Turale S. Barriers to quality of work life among Bangladeshi nurses: a qualitative study. Int Nurs Rev. 2019;66(3):396-403. Doi: 10.1111/inr.12540 